\title{
A "Ubiquitous Environment" through Wireless Voice/Data Communication and a Fully Computerized Hospital Information System in a University Hospital
}

\author{
Eisuke Hanada ${ }^{1}$, Shusaku Tsumoto ${ }^{1}$, and Shotai Kobayashi ${ }^{2}$ \\ ${ }^{1}$ Division of Medical Informatics \\ ${ }^{2}$ Exective Director, Shimane University Hospital, \\ Enya-cho. 89-1, 693-8501 Izumo, Japan \\ \{e-hanada, tsumoto, skdr3nai\}@med.shimane-u.ac.jp
}

\begin{abstract}
Fully computerized hospital information systems (HIS) are spreading in Japanese hospitals. Most HIS consist of server computers, terminals, a database, and a LAN. The introduction of HIS has enabled quick communication between doctors and staff and the immediate dissemination of patient information. Installation of a wireless data communication system compatible with a HIS has been reported to improve efficiency. However, also necessary is a voice communication system that can transmit instructions quickly in emergencies, such as a sudden change in the health status of an inpatient. In the Japanese medical community, "An environment in which access and the sharing of information are possible anywhere and at all times" is called a "ubiquitous environment." In order to attain such an environment, a telecom infrastructure with a mobile communications network is very important to voice and data communication. Here, we show the "ubiquitous environment" realized in Shimane University Hospital and how it has improved efficiency.
\end{abstract}

Keywords: Ubiquitous Environment, Electronic Hospital Information System, Wireless LAN, Mobile Voice Communication, Labor efficiency.

\section{Introduction}

Because most Japanese doctors do not employ secretaries, they have traditionally transmitted patient information and instructions for patient care in handwriting on paper. This is also true for the nursing staff. Computers have been widely installed in Japanese hospitals over the past 30 years. The original purpose was to calculate costs and to bill the patients. In recent years, with improvements in the performance of computers and databases and rapidly increasing data transfer rates for local area networks, LAN, the installation of Hospital Information Systems (HIS) has spread quickly in Japanese hospitals. Currently, the main purposes of HIS installation are to store and transmit information related to prescriptions, examinations, and the medical instructions of doctors. However, because there are no standards for HIS in Japan, each system is built around the functions needed by the hospital into which it is installed. However, because of the expense of the hardware, it has not been possible 
to install a sufficient number of terminals. With the evolution of HIS, it has become indispensable to place one or more terminals in outpatient consultation rooms. Few hospitals can afford terminals at each sickbed in their wards, so terminals are generally placed only at the staff stations.

The introduction of computers, databases, and LANs not only enables the rapid transfer of instructions by a doctor, but also enables the immediate sharing of patient records. However, to prepare for emergencies, such as sudden changes in the condition of an inpatient, adding a voice communication system to the data communication system is also necessary.

In the medical community in Japan, "An environment in which access and the sharing of information are possible anywhere and at all times" is called a "ubiquitous environment." In order to attain such an environment, a telecom infrastructure with a mobile communications network is very important to voice and data communication. Here, we introduce the "ubiquitous environment" currently in place in a university hospital and discuss its success in improving labor efficiency.

\section{The Computerized Hospital Information System}

Shimane University Hospital (hereafter, SUH) is an advanced hospital with 616 sickbeds and about 350 doctors. It has 11 general wards, a psychiatric ward, an ICU, and an NICU. Each general ward has on average about 50 sickbeds.

At SUH, many functions have been added since the HIS was introduced about 20 years ago. As a result, electronic storage of patient and nursing records (September, 2006) and the full digitalization of radiological data (April, 2008) have been realized. Also, online input and transmission of medical information, such as diagnosis, has been done since November 2006.

For about twenty years many hospitals have had electronic systems for recording prescriptions and medical examinations. However, in many hospitals patient treatment records and instructions for patient care given by doctors to the nursing staff are not yet computerized. This is also true of many functions unique to the nursing staff. Few hospitals have computerized systems to deal with the records of the co-medical staff, for example, consultations concerning medication by pharmacists or nutritional guidance by dietitians. In SUH, all aspects of the hospital have been incorporated into our HIS. SUH has an advanced system that has created a "ubiquitous environment".

In the HIS of SUH, users are categorized by their job description and affiliation and are allowed access only to that information judged necessary. Permission for access to data is classified as follows: reference only or permission to create or rewrite. For data protection, all of the server hardware, storage systems, and the networks between servers are backed up by duplicate systems. A monitoring system for the operation of the server, etc. is also in place.

Users can refer to any information within their authority using a common application to enter their ID and password at any terminal. Thus, all the staff members at SUH can work in a paperless environment, except for documents on which signatures are required. Only a few hospitals in Japan have attained an electronic environment on this scale.

In addition to the systems described above, in 2003 SUH started a patient information sharing system by linking our system to other hospitals and clinics (an 
inter-regional collaboration system, ICS). In Japan, a hospital in charge of a patient's treatment charges according a scale set by the Ministry of Health that is based on the requirements for treatment and the severity of a disease. Doctors often move their patients to other hospitals when specialized treatment is necessary, then again take charge of their care when they improve specialized treatment is no longer necessary. In such cases, the doctor refers the patient and writes a letter of introduction, which includes a summary of his treatment. In the ICS, all pre-registered doctors are given and ID and password, which allows them access to the system, allowing them to conveniently submit the introduction letters by computer. The ICS server is one of a number of servers in our HIS. By inserting a firewall system between the ICS server and other servers, direct access is denied to other, unauthorized areas of the HIS from outside SUH.

The functions included in the hospital information system of SUH are shown in Fig. 1.

\begin{tabular}{|c|c|c|c|}
\hline \multirow[b]{2}{*}{ Medicine section system } & \multirow{7}{*}{ 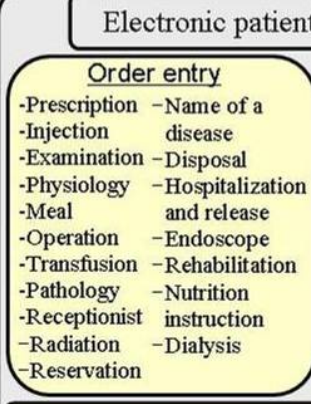 } & record system & \multirow{2}{*}{$\begin{array}{l}\text { Medical accounting system } \\
\text { Credit management system }\end{array}$} \\
\hline & & & \\
\hline $\begin{array}{c}\text { Medical imaging system } \\
\text { Radiation / endoscope / } \\
\text { ultrasonic image }\end{array}$ & & $\begin{array}{l}\text { - A nursing care } \\
\text { plan/diagnosis } \\
\text { - Nurse's record }\end{array}$ & $\begin{array}{c}\text { Management support } \\
\text { system }\end{array}$ \\
\hline Transfusion section system & & - Patient DB / summary & $\begin{array}{c}\begin{array}{c}\text { Supply management } \\
\text { system }\end{array} \\
\end{array}$ \\
\hline $\begin{array}{c}\text { Physiology performance } \\
\text { examination system }\end{array}$ & & $\begin{array}{l}\text { order/implementation } \\
\text { - A worksheet / care }\end{array}$ & Radiation section system \\
\hline $\begin{array}{c}\text { Optical medical medical- } \\
\text { examination system }\end{array}$ & & $\begin{array}{l}\text { sheet } \\
\text { - A heat type table/ } \\
\text { collating }\end{array}$ & $\begin{array}{c}\text { Nursing administration } \\
\text { system } \\
\text { Service/managed diary }\end{array}$ \\
\hline Operation section system & & & \multirow[b]{2}{*}{$\begin{array}{c}\text { Inter-regional collaboration } \\
\text { system }\end{array}$} \\
\hline $\begin{array}{c}\text { Nutrition management } \\
\text { room system }\end{array}$ & \multicolumn{2}{|c|}{ A leaving hospital summary / report / clinical path } & \\
\hline $\begin{array}{l}\text { Rehabilitation section } \\
\text { system }\end{array}$ & \multicolumn{2}{|c|}{ A problem / chart statement / Schema } & DPC coding system \\
\hline \multirow[t]{2}{*}{ Pathology section system } & \multicolumn{2}{|c|}{ A reference chart / DWH / indication / cooperation DB } & $\begin{array}{c}\text { Clinical history } \\
\text { management office system }\end{array}$ \\
\hline & \multicolumn{2}{|c|}{$\begin{array}{l}\text { A medical-examination document / letter of introduction } \\
\text { of the House / memo }\end{array}$} & Clinical laboratory system \\
\hline
\end{tabular}

Fig. 1. Functions of the HIS at SUH (presented by Toshiba Sumiden Medical Information Systems Corp., Japan)

The HIS of SUH currently consists of about 45 servers and over 800 terminals that are connected using wired/wireless LAN.

\section{Data Sharing Using Wireless LAN}

The hospital building of SUH has six floors. Each floor is $110 \mathrm{~m}$ long, east to west, with a staff station in the center (see Fig. 2). The nursing staff on each floor is divided into two groups, one for the east and one for the west wing. In the daytime, eight to ten nurses are assigned to each nurse unit, with about three nurses working at night. 
Wireless LAN (IEEE802.11a) was installed in all wards except for the ICU and NICU in October of 2003. At the time the wireless LAN was installed, 72 computers (hereafter, WLAN terminal) were connected to the HIS, as shown in Fig. 3. This number was determined based on the number of nurses working at that time. The present number of WLAN terminals is 110 at 13 access points (AP) on each floor, as shown in Fig. 2. The wireless LAN of SUH is exclusively for staff use. The system, which includes MAC Address filtering of AP, is secure and there have been no problems such as unauthorized use. The frequency of the electromagnetic signals specified by the IEEE802.11a standards is in the $5.2 \mathrm{GHz}$ band, and the maximum output power is about $150 \mathrm{~mW}$. The results of our irradiation experiments with 5.2 $\mathrm{GHz}$ electromagnetic waves on medical devices confirmed that this frequency has no influence on medical devices, if the access point and wireless network card in the PC are as approved by Japanese law [1].

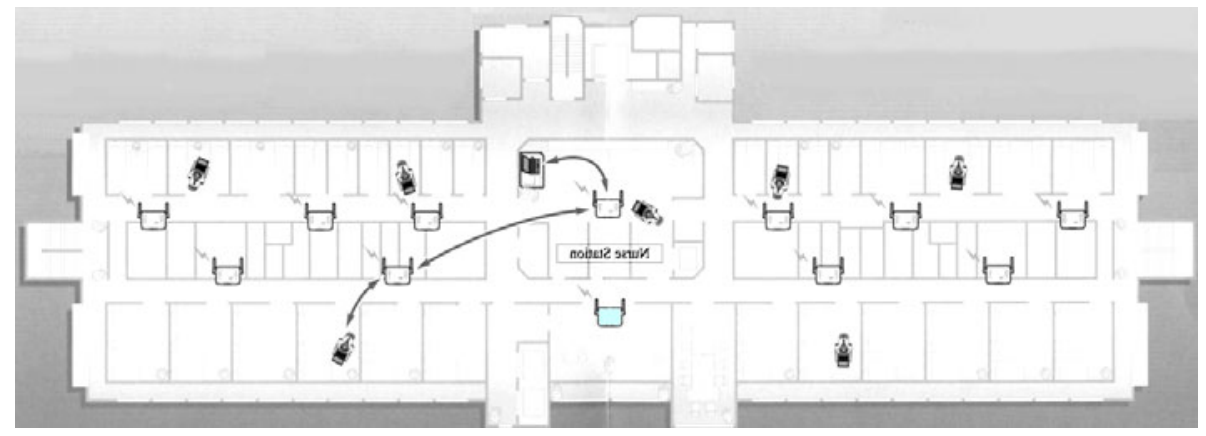

Fig. 2. Location of the SUH wireless LAN AP's on one floor (One AP, not shown, is in the "patient counseling room")

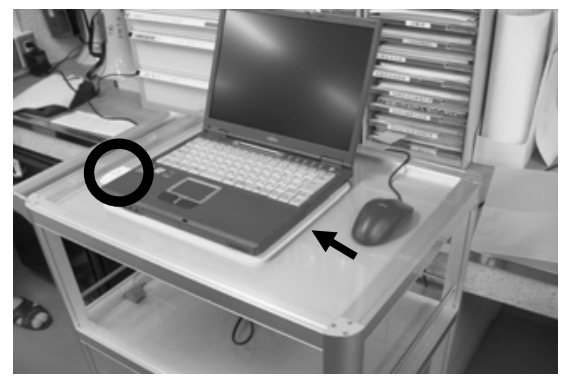

Fig. 3. A wireless LAN terminal at SUH (circle, wireless LAN card; arrow, a vibrationabsorbing mat)

\section{Labor Efficiency Improvement by Mobile Voice Communication}

At SUH, Personal Handy-phone System handsets (PHS, WILLCOM inc.) have been distributed to almost all doctors since November of 2004, which has enabled quick voice transfer of information and medical instructions. Other designated staff 
members have access to these phones, as do the safety management nurse and the facility maintenance staff. Currently, approximately 450 handsets are in use. Because the output power of the electric signals emitted by PHS handsets is weak, $80 \mathrm{~mW}$ maximum, there is almost no influence on medical devices [2]. These PHS handsets can accept calls from any number, but are pre-set so that only three numbers can be dialed. The usage fee is the equivalent of 7 to 8 US dollars monthly per handset.

In addition, one or two PHS handsets for which the monthly charge is fixed can be assigned as needed to the pharmacy and each ward. Quick, charge-free communication with doctors can be attained using these handsets. For example, a pharmacist can confirm a prescription quickly. Also, the nurse can receive a doctor's assistance at times of sudden changes in the condition of a patient. The use of these handsets has reduced the time wasted by physically looking for a doctor, which has greatly contributed to the improvement of labor efficiency. This was confirmed in a study of the number telephone calls: The number was greatly reduced by the introduction of PHS (See Table 1 [3]).

Table 1. Number of phone calls received before and after PHS installation

a) Number of calls by place of origin and the reduction rate (Weekdays 8:30 5:00)

\begin{tabular}{|c|c|c|c|c|}
\hline Origin of call & Pharmacy & Clinical lab. & $\begin{array}{c}\text { Hosp. Affairs } \\
\text { Section }\end{array}$ & Others \\
\hline Before introduction & 118 & 92 & 111 & 982 \\
\hline After introduction & 23 & 66 & 38 & 412 \\
\hline Number Reduced & 95 & 26 & 73 & 560 \\
\hline Reduction rate $(\%)$ & $\mathbf{8 0 . 5}$ & 28.3 & $\mathbf{6 5 . 8}$ & 57.0 \\
\hline
\end{tabular}

b) The total number of calls over five weekdays

\begin{tabular}{|c|c|c|}
\hline Section & Calls before introduction & Calls after introduction \\
\hline Wards & 1216 & 588 \\
\hline Visitor sections & 458 & 356 \\
\hline Other sections & 116 & 212 \\
\hline Total & 1790 & 1126 \\
\hline
\end{tabular}

In addition, SUH has permitted cellular phone use under certain conditions in some areas of the hospital since January of 2004 [1]. Permission for cellular-phone use is a difficult problem for hospitals [4]. In order to insure cellular phone safely, it is 
necessary for measures to be taken against the following problems; electromagnetic interference (EMI) with medical devices, noise by the speaker or ring tone, improper personal information disclosure using the camera/movie recording function, and lack of concentration on work while talking over the telephone. The output power of signals emitted from Japanese cellular phone handsets is currently $250 \mathrm{~mW}$ or less. Thus, for the convenience of the patients, the conditional use of cellular phones in hospitals can be safely permitted.

\section{Discussion}

\section{Mobile Communication System}

As shown above, SUH can be considered a pioneering hospital with a "ubiquitous environment". Our follow-up data for the introduction of the electronic data retrieval and storage system and the wireless LAN to the HIS show them to have been successful in allowing us to implement our "ubiquitous environment" and that it has been safe and efficient. The nurses who work in our wards are the main users of the WLAN terminals. An important factor in our success was that we have carefully considered the merits and limits of the various systems to be used and took precautions to insure the safe and efficient usage of our wireless LAN before installing the systems.

The number of AP installed for the wireless LAN in SUH now thirteen for each floor, the minimum necessary number. Some nurses have reported that the range of the signals is not satisfactory in some sickrooms. The range of an electromagnetic wave has been shown to be influenced by the materials used in the construction of walls and doors [5]. Unfortunately, adding to the number of AP's would increase the need for equipment maintenance and require remodeling expenses due to an increased need for wiring, so we must maintain the current level. Although some simulations of electromagnetic wave range have been done [6-8], the huge computational complexity needed to perform this type of simulation in an actual hospital setting has resulted in only simple simulations having been done.

\section{Computerization of Medical Information}

Medical records have long been handwritten in Japan, and doctors often include drawings in their records. When computerized medical records are proposed, there is often opposition by these doctors. At SUH, this opposition was reduced by the introduction of a system that can scan drawings and by the executive director who exercised strong leadership.

The Ministry of Health, Labour and Welfare (MHLW) of Japan requires hospitals that computerize medical records to adopt the following conditions to insure information security.

- Confidentiality : limitation of the right to access

- Integrity : verification and backup of data, system duplication, etc.

- Availability : certainty of access by approved users

The HIS of SUH fulfills these conditions. 
Many Japanese hospitals are introducing "critical path" (CP)" systems to standardize patient care. A CP is drawn up each disease and every surgical procedure. The CP describes the patient care that will be given during hospitalization, and in some cases, the $\mathrm{CP}$ is divided into timeframes. In CP, setting up a target "outcome" for every treatment and including exceptions to the treatment protocol as "variance" is recommended. $\mathrm{CP}$ has the benefits of promoting efficacy by eliminating unnecessary examinations and shortening the duration of hospitalization [9]. CP has been beneficial in our effort to raise medical efficiency in Japanese hospitals. From the viewpoint of the HIS manager, a CP can be considered a "packed order" that includes a wide variety of directions that can be selected from and that is used to promote standardized care. Pathological and bio-chemical tests, physiological function examinations, radiological examinations, surgeries, prescriptions, medical treatments, treatment instructions to nurses, etc. are included in each CP. Because all of the above are computerized at SUH, these standardized $\mathrm{CP}$ have become an integral part of the HIS. Since December 2008, SUH has been able to incorporate a unified, multidisciplinary $\mathrm{CP}$ that includes nursing services into our HIS. The number of CP currently registered and employed exceeds 350 . The use of the CP in our HIS has reduced the time burden on our doctors and made them more efficient and effective.

\section{Installation of the PHS and Telemedicine System}

Shimane Prefecture is a rural area in western Japan. In this area, a shortage of doctors has long been a serious problem. To ameliorate this problem, doctors are dispatched from SUH to other hospitals. PHS serves as a communication medium with the doctors who work outside SUH. The number of doctors currently working at SUH is also insufficient. Therefore, communication between doctors and the co-medical staff is critical, and PHS contributes to our efficiency and patient safety.

The use of IP phones or VoIP (Voice over IP) would eliminate almost all of the cost of telephone calls, even when using public systems. Unfortunately, VoIP and IP phones are not widely used in Japan. A problem with the introduction of VoIP devices for mobile communications is that they are much more expensive than PHS and cell phone handsets. The low cost is one of the reasons SUH adopted PHS. In Japan, private corporations have no national standards or policies to guide their construction and maintenance of the regional public broadband mobile communications networks. Thus, although this service is accessible in major cities, their introduction to lightly populated areas like Shimane Prefecture has been slow, and at present no companies have plans to begin this service here in the foreseeable future. The Japanese government has a plan that proposes the use of information and communication technology (ICT) to compensate for the regional medical specialist shortage; however, because this would require a broadband communication network, it will require much time and effort to realize an environment in which this ICT strategy can be successful. Because of the above problems, SUH utilizes PHS and has introduced an online telemedicine support system [10] in which specialized medical advice is possible at a transmission speed of $1 \mathrm{Mbps}$ in one direction. 


\section{Designs for the Future}

\section{Wireless LAN in Our New Ward Building}

A new ward is under construction at SUH, with a completion date in the spring of 2011. Wireless LAN has been approved, and its specifications will meet the specifications of the current IEEE802.11n. At the time of installation, a new channel design will be used and electromagnetic shielding is being built into the ward to insure a safe electromagnetic environment.

\section{Plans for New ICT Systems}

The following new systems are also being planned: A medical device management system using wireless LAN and RF-ID tags and a nurse call system (NCS), connected to the HIS, that uses VoIP. In the medical device management system, an RF-ID tag will be attached to each medical device to prevent the loss of this expensive equipment. This system also allows us to monitor the current location of any device, to track patient information by the user of the device, and to monitor the operating condition of each device. In terms of the location of a device, high precision, such as to the nearest few centimeters, is not necessary. However, the influence of the frequency of RF-ID tags on the medical equipment with which it is to be used is important, so we are doing investigations to insure safety. Also, in large Japanese hospitals, a central office manages medical devices and distributes them to the area of the hospital they are needed. We plan to use RF-ID tags to assist in the management of this system. Because the RF-ID tag itself is expensive, their use with a bar code is also being considered. As for NCS, client/server systems with portable remote terminals are currently in use in many large Japanese hospitals. Our NCS will not only focus on voice communication as is done in the systems currently in use, but will eventually be part of our HIS that includes VoIP.

\section{A New, Safe and Secure Server Room}

The installation of a new HIS server room is also planned in order to increase security. Advanced preparation for disasters and personnel management are lacking in the HIS server rooms of many Japanese hospitals. Because Japan has many earthquakes, a quake-absorbing function is indispensable and will be built into our server room. In addition, we intend to substantially improve our firefighting equipment, take measures to protect against information leaks, and make improvements to the power supply equipment and air conditioning in the new server room Also, because of rapid changes in technology, the HIS must be upgraded and equipment replaced approximately every five years.

\section{Conclusion}

SUH's progressive HIS system has allowed us to realize our pioneering goal of creating a "ubiquitous environment". Our program has been so successful that the SUH staff has come to consider the use of PHS and wireless LAN with electronic 
medical records to be common sense. It will be important for us to continue to develop the scale of and functions included in our "ubiquitous environment".

\section{Acknowledgement}

This investigation was partially supported by the Japan Society for the Promotion of Science (No.20390151).

\section{References}

1. Hanada, E., Nakakuni, H., Kudou, T.: Safe and Efficient Use of Wireless Communication in a Large Hospital. In: Medinfo. 2007, Brisbane, p. 442 (2007)

2. Hanada, E., Antoku, Y., Tani, S., et al.: Electromagnetic interference on medical equipment by low-power mobile telecommunication system. IEEE Transactions on Electromagnetic Compatibility 42(4), 470-476 (2000)

3. Hanada, E., Fujiki, T., Nakakuni, H., Sullivan, C.V.: The effectiveness of the installation of a mobile-voice-communication system in a university hospital. Journal of Medical Systems 30(2), 101-106 (2006)

4. Derbyshire, S.W.G., Burgess, A.: Use of mobile phones in hospitals. BMJ 333, 767-768 (2006)

5. Hanada, E., Watanabe, Y., Antoku, Y., et al.: Hospital construction materials: Poor shielding capacity with respect to signals transmitted by mobile telephones. Biomedical Instrumentation \& Technology 35(4), 489-496 (1998)

6. Yee, K.: Numerical Solution of Initial Boundary Value Problems Involving Maxwell's Equations in Isotropic Media. IEEE Transactions on Antenna Propagation 14(3), 302-307 (1966)

7. Ji, Z., Li, B.H., Wang, H.X., et al.: Efficient ray-tracing methods for propagation prediction for indoor wireless communications. IEEE Antennas And Propagation Magazine 43(2), 41-49 (2001)

8. Hoppe, R., Wertz, P., Landstorfer, F.M., et al.: Advanced ray-optical wave propagation modelling for urban and indoor scenarios including wideband properties. European Transactions on Telecommunications 14(1), 61-69 (2003)

9. Ramos, M.C., Ratliff, C.: The Development and Implementation of an Integrated Multidisciplinary Clinical Pathway. Journal of Wound, Ostomy \& Continence Nursing 24(2), 66-71 (1997)

10. Hanada, E., Ikebuchi, K., Miyamoto, M., et al.: An Interactive Medical Support System for Rural Area in Dermatology. In: The 11th International Congress of the Iupesm, Medical Physics And Biomedical Engineering World Congress 2009, Munich, vol. 05/07, p. 1 (2009) 